\title{
CONSTRUCTION OF THE NEW BELGIAN MOTOR THIRD PARTY \\ TARIFF STRUCTURE
}

\author{
By JEAN LEMAIRE \\ Wharton School, University of Pennsylvania
}

\begin{abstract}
The paper describes how a study group, appointed by the Belgian Professional Union of Insurance Companies, designed a new tariff structure in motor third party liability. Particular emphasis was given to the construction of a more efficient bonus-malus system.
\end{abstract}

\section{KEYWORDS}

Automobile insurance; bonus-malus systems.

In Belgium, the present statutory tariff for the computation of motor third party liability premiums is prescribed by the Ministerial Decree of April 14th, 1971. Every company thus has to apply a tariff that introduces three rating factors:

(i) the power of the vehicle

(ii) the bonus-malus system, consisting of 18 classes as follows:

\begin{tabular}{rc}
\hline Class & Premium level \\
\hline 18 & 200 \\
17 & 160 \\
16 & 140 \\
15 & 130 \\
14 & 120 \\
13 & 115 \\
12 & 110 \\
11 & 105 \\
10 & 100 \\
9 & 100 \\
8 & 95 \\
7 & 90 \\
6 & 85 \\
5 & 80 \\
4 & 75 \\
3 & 70 \\
2 & 65 \\
1 & 60 \\
\hline
\end{tabular}

The transition rules allow a reduction of one class for each claim-free year and penalize policyholders by two classes for the first claim and by three classes for each additional claim reported during the same year.

Moreover, a policyholder who does not make a claim for four consecutive years but who is nevertheless in a class higher than 10 , is automatically brought down to class 10 . 
(iii) the use of the vehicle: business users enter the system in class 10 , nonbusiness users in class 6 .

At the end of 1983, the "Ministère des Affaires Economiques" suggested that companies should undertake a thorough reform of this tariff. The UPEA (Professional Union of Insurance Companies) appointed a study group, under the chairmanship of the author of this paper, whose main task was to recommend a new tariff structure to the insurance companies and the control authorities.

In the actuarial literature, tariffing is usually presented as a purely statistical problem (see, for instance, VAN EEGHEN, GREUP and NIJSSEN (1983)): clearly this is not the case in practice, where a complex system of regulations, sociopolitical constraints, marketing considerations and historical reasons (not to mention the conservatism of many insurers) influence the final tariff structure. It was, for instance, obvious from the very beginning that simplicity was a major concern to most interested parties; an increase in the number of tariff variables from the present 3 to 7 or 8 would certainly have been vetoed by the Ministère des Affaires Economiques. Moreover, the control authorities clearly hinted, during informal preliminary meetings, that they did not like the idea of a priori classification variables, their main argument being that the fact that a policyholder is young or lives in a densely populated area does not necessarily imply that he is more likely to cause accidents. We were strongly recommended to emphasize a posteriori rating.

As many research studies performed all over the world have shown that merit rating constitutes by far the most efficient way of classifying policyholders, it was then clear to the study group that its main task was the improvement of the bonus-malus system.

The study group was able to persuade six of the largest companies to make available statistical data concerning their whole portfolio. Consequently a tape containing information relating to over 750,000 policyholders, observed in 1982 , was created. Most of the classical models of the actuarial literature were then applied to select the significant variables and to construct a better bonus-malus system. Three issues were considered to be of paramount importance for the construction of the new bonus-malus scale: the stability of the premium income, the fairness to the policyholders and the magnitude of the hunger for bonus.

\section{The Stability of the Premium Income of the Companies}

After the introduction of the present system in 1971, the insurers experienced a nightmare, owing to the progressive increase in the average premium discount brought about by the transition rules, coupled with governmental refusals to raise the average premium level accordingly. Nowadays, the average policyholder profits by a discount of $33 \%$, i.e. he is situated between classes 2 and 3. Over $61 \%$ of the policyholders enjoy the maximum discount, over $77 \%$ find themselves in one of the three lower classes; less than $0.7 \%$ of the policies are in the malus zone! Consequently the companies suffered great losses in the past few years; out 
of a premium income of 2,365 millions, a large company allowed 793 millions of bonuses in 1985, while it recovered only 2.3 millions in maluses!

Consequently, an absolute constraint on the implementaton of the new system was that the same problem must not arise again; a further increase in the average discount cannot be tolerated, even if the overall claim frequency drops slightly.

In order to forecast the evolution of the premium income, a simulation program was devised, based on the classical negative binomial model; assuming that the number of claims of a policyholder characterized by his claim frequency $\lambda$ conforms to a Poisson distribution

$$
p_{k}(\lambda)=e^{-\lambda} \lambda^{k} / k ! \quad k=0,1, \ldots,
$$

while $\lambda$ is distributed in the portfolio according to a $\Gamma$ structure distribution

$$
u(\lambda)=\tau^{a} e^{-\tau \lambda} \lambda^{a-1} / \Gamma(a),
$$

it is well known that the resulting distribution of the number of claims in the portfolio conforms to a negative binomial distribution

$$
p_{k}=\int_{0}^{\infty} p_{k}(\lambda) u(\lambda) d \lambda=\left(\begin{array}{c}
k+a-1 \\
k
\end{array}\right)\left(\frac{\tau}{1+\tau}\right)^{\prime \prime}\left(\frac{1}{1+\tau}\right)^{k} .
$$

The parameters of the $\Gamma$ were chosen in such a way that its mean is equal to 0.10 , while its variance equals 0.107 . The annual percentage of new policies was set equal to $6.3 \%$.

Using the simulation program, we have computed the stationary average level for some of the most representative bonus-malus systems in force in the world (these systems are summarized in the Appendix). As stationary levels are difficult to compare, we have also computed the "relative stationary average level", defined as

$$
\frac{\text { stationary average level }- \text { minimum level }}{\text { maximum level }- \text { minimum level }} .
$$

Expressed in percent, it is an index which situates the level of the average policyholder, if the lowest premium level is set equal to zero and the highest one to 100 .

\section{The Fairness to the Policyholders}

The efficiency of a bonus-malus system is defined as follows (LEMAIRE, 1985, chapter 17). Let an $s$-class bonus-malus system be defined by

the premium levels $b_{i} \quad i=1, \ldots, s$

the transition rules $T_{k}(i)=j$, for all $i, j, k$ : the policy is transferred from class $i$ to class $j$ if $k$ claims have been reported.

$v_{i}(\lambda)$, the discounted expectation of all the premiums charged to a policyholder 
of claim frequency $\lambda$ starting in class $i$, has to satisfy the set of equations

$$
\begin{array}{ll}
v_{i}(\lambda)=b_{i}+\beta \sum_{k=0}^{\infty} p_{k}(\lambda) v_{T_{k}(i)}(\lambda) \quad \begin{array}{l}
\beta=\text { discount factor } \\
i=1, \ldots, s
\end{array}
\end{array}
$$

assuming an infinite horizon. For an acceptable bonus-malus system, $v_{i}(\lambda)$ must be an increasing function of $\lambda$. Ideally, this dependence should be linear: an increment $d \lambda / \lambda$ in the claim frequency should produce an equal change, $d v_{i}(\lambda) / v_{i}(\lambda)$, in the expectation of all payments. The system is called perfectly efficient if

$$
\frac{d v_{i}(\lambda) / v_{i}(\lambda)}{d \lambda / \lambda}=1
$$

As a general rule, however, the change in premiums is much less than the change in claim frequency. Consequently, we define the efficiency of a bonus-malus system by

$$
\mu_{i}(\lambda)=\frac{d v_{i}(\lambda) / v_{i}(\lambda)}{d \lambda / \lambda}
$$

So the efficiency is defined as the elasticity of the discounted expectation of all payments with respect to the claim frequency. It is a measure of the fairness of the system to the policyholder. It can be computed for all starting classes and all values of $\lambda$. For presentation purposes, only the efficiency corresponding to $\lambda=0.10$ ( $=$ the current observed claim frequency) is shown in Tables $1,4,5$ and 10 for a new non-business driver. $\beta$ was chosen to correspond to an inflation rate of $7 \%$ (in practice, the efficiency appears to be extremely insensitive to the choice of $\beta)^{1}$

\section{The Magnitude of the Hunger for Bonus}

Any strengthening of the bonus-malus system, by way of stiffer transition rules for instance, will automatically induce a higher propensity for the policyholders to bear claims personally. This is not necessarily to be considered as desirable; if the main objective of a bonus-malus system is to achieve a better separation of the good and the bad risks (and - possibly - to persuade policyholders to drive more carefully), the objective is certainly not to transfer most claims from the insurer to the insured. So any bonus-malus system that would force (or induce) a policyholder to bear himself a claim of, say, over 100,000 Belgian francs might be considered to penalize the policyholder excessively. The hunger for bonus associated with each proposed bonus-malus system was estimated by a procedure described in LEMAIRE (1985), chapter 18.

1. "Efficiency" might be a somewhat misleading word, since it has many different meanings in statistical and actuarial literature (for instance, in statistics, it usually refers to the precision of an estimator, in terms of quadratic loss). We used the terminology introduced by LOIMARANTA (1972), adopted since by many authors. 
The assumptions were:

(i) Claims distribution: all Belgian companies, 1970 indexed. It is necessary to work with a distribution in respect of such an early year since the later observations are distorted by hunger for bonus (the optimal retentions appear to be quite insensitive to the claims distributions; indeed a subsequent analysis, based on the 1983 distributions of cabs, not subject to bonus-malus, produced nearly exactly the same results).

(ii) $\lambda=0.144$. The reason for this choice is that the actual observed claim frequency in Belgium, $\lambda=0.10$, is already influenced by the hunger for bonus: the observed frequency is substantially smaller than the "real" one, due to the non-declaration of small claims. The computation of the optimal retentions of course uses the "real" frequency. Its value was chosen in such a way that the algorithm, applied to the Belgian bonus-malus system, forecasts an observed claim frequency of 0.10 .

(iii) The commercial premium at level 100 for the Belgian system was set equal to 20,000 francs, an amount that differs little from the average observed premium in 1984. In order to be able to perform valid comparisons with systems in other countries, the premium charged at level 100 for the other systems was computed in such a way that the average premium (if all claims are reported) was the same for all countries (indeed the class labelled "level 100 " is situated at quite different positions, depending on the country: to have adopted the same basic premium would have drastically distorted the results).

For each system we have computed the average optimal retention (weighted using the stationary class probabilities) and the maximal optimal retention. The results are summarized in Table 1.

We notice immediately that the reform of the Belgian bonus-malus system is really overdue. Despite having the third-largest number of classes, the Belgian system has the lowest efficiency (even lower than the 5-class system of Quebec),

TABLE 1

\begin{tabular}{|c|c|c|c|c|c|}
\hline Country & $\begin{array}{c}\text { Efficiency } \\
(\%)\end{array}$ & $\begin{array}{c}\text { Stationary } \\
\text { average } \\
\text { level }\end{array}$ & $\begin{array}{c}\text { Relative } \\
\text { stationary } \\
\text { average } \\
\text { level }(\%)\end{array}$ & $\begin{array}{c}\text { Average } \\
\text { optimal } \\
\text { retention }\end{array}$ & $\begin{array}{c}\text { Maximal } \\
\text { optimal } \\
\text { retention }\end{array}$ \\
\hline Belgium & 6.7 & 70.3 & 7.4 & 5,828 & 52,154 \\
\hline France & 16.8 & 76.7 & 8.9 & 10,516 & 107,830 \\
\hline United Kingdom & 10.6 & 40 & 7.7 & 12,251 & 28,586 \\
\hline $\begin{array}{l}\text { Netherlands } \\
\text { (Starting class 2) }\end{array}$ & 20.1 & 58 & 31.1 & 16,296 & 64,226 \\
\hline Sweden & 17.7 & 41.5 & 22 & 26,662 & 48,441 \\
\hline Switzerland & 22.2 & 72 & 12 & 10,869 & 114,690 \\
\hline Germany & 12.3 & 66.5 & 16.6 & 9,236 & 39,808 \\
\hline Quebec & 6.9 & 94 & 12.7 & 7,731 & 18,427 \\
\hline
\end{tabular}


the lowest relative stationary average level, and it even produces one of the highest maximal optimal retentions! So, despite being rather sophisticated, this system manages to be at the same time the most unfair to the policyholders and the most unbalanced to the insurers! The analysis of Table 1 shows that the efficiency depends on the number of classes, on the steepness of the premium scale, and above all on the transition rules. A subsidiary analysis proved that special rules to accelerate the descent from high malus zones to the basic level (like in France or in Belgium), besides rendering the system non-Markovian, substantially reduce the efficiency. Therefore it was decided

(i) to adopt a Markovian system;

(ii) to retain the present 18 classes; the present number of classes was judged adequate; the recommendation of a system with less than 18 classes was only briefly examined, considering that the new system would be the cornerstone of the tariff structure. On the other hand, to introduce more than 18 classes would be unfair to policyholders who improve after bad early driving-years: under the new transition rules, 17 claim-free years would be necessary to move from the top level to the bottom one; this is more than enough compared with the average duration of the driving life. Moreover, a slight modification of the number of classes was shown to have only negligible consequences as far as premium income and efficiency are concerned;

(iii) to alter only slightly the premium levels, while strengthening the transition rules.

After lengthy trial-and-error runs, two proposals eventually emerged (see Table 2) as well as three sets of transition rules (see Table 3). Harsher penalties were not even considered (although technically entirely justifiable) for they would certainly have been vetoed by the Control Authorities.

The main results of the program runs are summarized in Tables 4 and 5 . Note that the stationary average level depends on the starting class, due to the constant flow of new policies. Also note that the basic premium for each system was again set in such a way that the average premium remains unchanged; this explains why the maximal optimal retentions are smaller when the strong penalties are introduced instead of the moderate penalties: the decrease of the basic premium more than offsets the effect of the stronger penalties.

The comparison of the two proposals led to the following conclusions:

(i) whatever the transition rules, the efficiency and the average level are only slightly better for proposal 2, while the optimal retentions for the upper classes are much higher. Clearly it is not worthwhile to "frighten" the policyholders with an upper level of 350 and retentions above 100,000 francs; consequently proposal 2 was abandoned.

(ii) Proposal 1, applied with the "strong" transition rules, leads to a system that would put Belgium far ahead of all European countries, as far as efficiency is concerned. Moreover, the average premium level would be expected to rise from the present 70.3 to over 85 , depending on the selected starting class. 
However, the optimal retentions are unacceptable: the adoption of those transition rules would nearly treble the effect of hunger for bonus.

Therefore the recommendation of the study group was the adoption of proposal 1 , with the "moderate" transition rules. Class 10 was selected as starting class, since it maximizes the efficiency (note the suppression of the differentiated entry level according to the use of the car: claims statistics for business and nonbusiness users do not differ significantly any more).

Figure 1 compares the efficiency curves of the proposed and of the old system; the marked shift to the left shows the improvement that the adoption of our new proposal would induce, for the most usual values of $\lambda$. The adoption of a more efficient bonus-malus system would undoubtedly have an effect on policyholders' behaviour; clearly the claim frequency would decrease, owing to the increased hunger for bonus and, possibly, to more careful driving. So the average premium level would most probably not rise to the forecast 93 . Could it be that the decrease in claim frequency would more than off set the effect of

TABLE 2

\begin{tabular}{rrrr}
\hline \hline & & & Premium level \\
\cline { 3 - 4 } Class & Present system & Proposal 1 & Proposal 2 \\
\hline 18 & 200 & 250 & 350 \\
17 & 160 & 230 & 310 \\
16 & 140 & 210 & 270 \\
15 & 130 & 195 & 230 \\
14 & 120 & 180 & 200 \\
13 & 115 & 165 & 180 \\
12 & 110 & 150 & 160 \\
11 & 105 & 140 & 140 \\
10 & 100 & 130 & 130 \\
9 & 100 & 120 & 120 \\
8 & 95 & 110 & 110 \\
7 & 90 & 100 & 100 \\
6 & 85 & 90 & 90 \\
5 & 80 & 80 & 80 \\
4 & 75 & 75 & 75 \\
3 & 70 & 70 & 70 \\
2 & 65 & 65 & 65 \\
1 & 70 & 60 & 60 \\
\hline
\end{tabular}

TABLE 3

\begin{tabular}{lccc}
\hline \hline & $\begin{array}{c}\text { "Mild" penalties } \\
\text { (present rules) }\end{array}$ & $\begin{array}{c}\text { "Moderate" } \\
\text { penalties }\end{array}$ & $\begin{array}{c}\text { "Strong" } \\
\text { penalties }\end{array}$ \\
\hline $\begin{array}{l}\text { Claim-free year } \\
\text { First claim }\end{array}$ & -1 & -1 & -1 \\
$\begin{array}{l}\text { Subsequent claim } \\
\text { in the same year }\end{array}$ & +2 & +3 & +4 \\
\hline
\end{tabular}




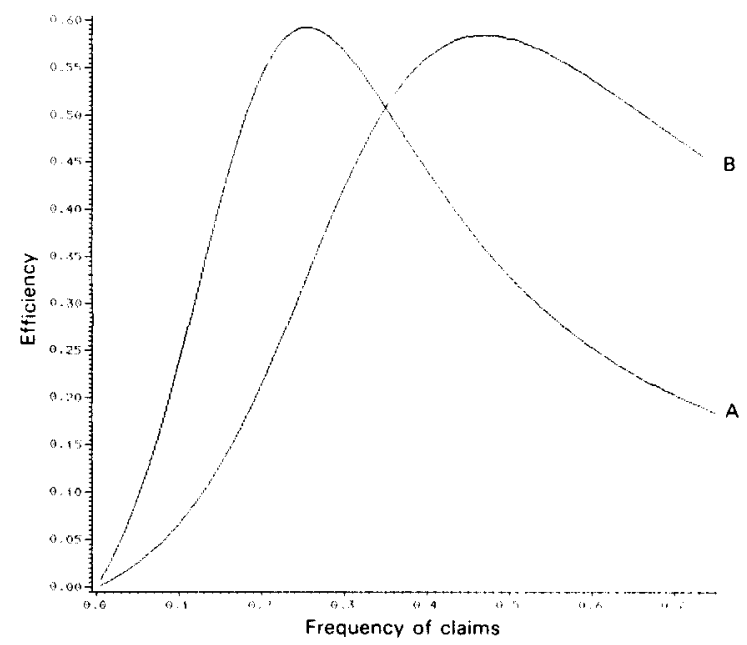

FIGURE 1. Efficiency curves for A, proposed system and B, old system.

TABLE 4

\begin{tabular}{|c|c|c|c|c|}
\hline \multirow{2}{*}{\multicolumn{2}{|c|}{ Proposal 1}} & \multicolumn{3}{|c|}{ Penalties } \\
\hline & & Mild & Moderate & Strong \\
\hline \multicolumn{5}{|l|}{ Efficiency $(\%)$} \\
\hline starting class: & 7 & 9.6 & 18.4 & 28.5 \\
\hline & 8 & 10.6 & 19.5 & 29.1 \\
\hline & 9 & 11.6 & 20.4 & 29.5 \\
\hline & 10 & 12.5 & 21.2 & 29.6 \\
\hline \multicolumn{5}{|l|}{$\begin{array}{l}\text { Stationary } \\
\text { average level }\end{array}$} \\
\hline starting class: & 7 & 73.7 & 80.0 & 85.6 \\
\hline & 8 & 77.4 & 83.9 & 90.0 \\
\hline & 9 & 81.7 & 88.5 & 94.7 \\
\hline & 10 & 86.9 & 93.0 & 99.4 \\
\hline \multirow{3}{*}{\multicolumn{2}{|c|}{$\begin{array}{l}\text { Average optimal } \\
\text { retention } \\
\text { Maximal optimal } \\
\text { retention }\end{array}$}} & 6,283 & 10,353 & 14,132 \\
\hline & & & & \\
\hline & & 69,612 & 76,984 & 74,679 \\
\hline
\end{tabular}

stronger transition rules, so that the average premium level would still decrease? We think we can rule out this possibility. Indeed, if all policyholders apply their optimal retention strategy, the algorithm forecasts a claim frequency of 0.0773 . As most insureds do not possess the computational ability to obtain a good estimate of their optimal retention and/or simply cannot afford to pay a significant amount from their own pockets to indemnify their victims, it is more probable that the observed claim frequency would not drop by much more than one percentage point. 
TABLE 5

\begin{tabular}{lrrrr}
\hline & & & Penalties & Strong \\
\cline { 3 - 4 } \multicolumn{1}{c}{ Proposal 2 } & & Mild & Moderate & \\
\hline Efficiency (\%) & & & & 32.5 \\
starting class: & 7 & 9.7 & 19.8 & 33.6 \\
& 8 & 10.9 & 21.2 & 34.6 \\
& 9 & 12.1 & 24.7 & 35.2 \\
Stationary & 10 & 13.3 & & 90.1 \\
average level & & & 81.7 & 94.0 \\
starting class: & 7 & 74.4 & 85.8 & 99.4 \\
& 8 & 77.9 & 90.6 & 104.0 \\
& 9 & 82.8 & 96.4 & 13,840 \\
Average optimal & 10 & 87.5 & & 106,040 \\
retention & & 6,279 & & 117,200 \\
Maximal optimal & & 111,190 & & \\
retention & & & & \\
\hline
\end{tabular}

Tables 6 and 7 show that, whatever the degree of awareness of hunger for bonus, the companies' income cannot decrease below the present level. In these tables, we present the stationary average level and the expected stationary distribution of policyholders, for various values of the claim frequency $\lambda$. Those values were determined by our simulation programme, varying $\lambda$ and keeping the ratio between the variance and the mean of the $\Gamma$ distribution equal to 1.07.

A comparison between Table 7 and the actual distribution of policyholders shows the dramatic improvement that the new system would introduce. Assume the claim frequency drops to 0.09 . It is forecast that only $35 \%$ of the policyholders would eventually receive the largest discount, instead of the present $61 \%$. 31.5\% would find themselves in the malus zone, instead of the present $0.7 \%$ ! Moreover, the policyholders would be much more evenly spread, at least in the classes 2 to 10 .

Note that, although the design of a new bonus-malus system was the main objective of the present tariff reform, some other modifications were proposed. The study group suggested introducing age of policyholder as a tariff variable. The initial proposal was to impose a surcharge of $20 \%$ if the vehicle may be driven by someone under 23 years of age. The surcharge was not to be compulsory; however, if a claim caused by a young driver occurred and the surcharge had not been paid, a heavy deductible was to be applied. During preliminary conversations, the Control Authorities made it clear that they would not consider this

TABLE 6

\begin{tabular}{lcccc}
\hline \hline Claim frequency & 0.07 & 0.08 & 0.09 & 0.10 \\
Stationary average level & 87 & 89 & 91.15 & 93 \\
\hline
\end{tabular}


TABLE 7

\begin{tabular}{|c|c|c|c|c|}
\hline \multicolumn{5}{|c|}{ Expected stationary distribution of policyholders $(\%)$} \\
\hline & \multicolumn{4}{|c|}{ Frequency } \\
\hline & 0.07 & 0.08 & 0.09 & 0.10 \\
\hline \multicolumn{5}{|c|}{ Class } \\
\hline 1 & 39.41 & 36.42 & 35.13 & $32.62-2.0 .0$ \\
\hline 2 & 4.55 & 4.90 & 4.33 & 4.64 \\
\hline 3 & 5.24 & 5.29 & 5.40 & 5.61 \\
\hline 4 & 5.98 & 6.22 & 6.42 & 5.92 \\
\hline 5 & 5.06 & 5.30 & 4.82 & 5.43 \\
\hline 6 & 5.63 & 5.35 & 5.77 & 5.98 \\
\hline 7 & 6.02 & 6.49 & 6.62 & 6.26 \\
\hline 8 & 6.75 & 6.74 & 6.58 & 6.97 \\
\hline 9 & 7.09 & 7.69 & 7.42 & 7.70 \\
\hline 10 & 8.17 & 8.40 & 8.61 & 9.15 \\
\hline 11 & 1.70 & 1.75 & 1.98 & 1.99 \\
\hline 12 & 1.20 & 1.32 & 1.79 & 1.85 \\
\hline 13 & 0.92 & 1.20 & 1.23 & 1.51 \\
\hline 14 & 0.46 & 0.71 & 0.96 & 1.04 \\
\hline 15 & 0.55 & 0.62 & 0.82 & 0.92 \\
\hline 16 & 0.38 & 0.66 & 0.81 & 0.85 \\
\hline 17 & 0.40 & 0.45 & 0.68 & 0.79 \\
\hline 18 & 0.49 & 0.49 & 0.63 & 0.77 \\
\hline
\end{tabular}

TABLE 8

\begin{tabular}{lcccc}
\hline Claim frequency & 0.07 & 0.08 & 0.09 & 0.10 \\
Stationary average level & 88.3 & 90.7 & 92.7 & 95
\end{tabular}

proposal favourably (as with the introduction of any new a priori variable). Therefore, the proposal was modified. The criterion "age of driver" is to be introduced in an a posteriori form: if a claim has been caused by a driver under 23 years of age, the policy will be moved upwards by one further class in the bonus-malus system. This means that the transition rules for young drivers would penalize the first claim by four classes, and any subsequent claim during the same year by five classes. This proposal was greeted very favourably by both the Control Authorities and the insurance companies, thanks to its simplicity; administrative expenses would be much lower as a result of applying differential transition rules than as a result of suggesting surcharges to all policyholders and trying to have the large deductibles paid by the drivers who caused an accident. Moreover, these new transition rules would have a very positive effect on the bonus-malus system, since the efficiency would rise to 0.2385 (the highest among all analysed European systems) and the stationary average level should increase somewhat, as shown in Table 8 .

As a final feature of this tariff reform, very harsh penalties were proposed in the case of claims under aggravating circumstances, again in the form of stiffer transition rules: a hit-and-run claim would be penalized by three supplementary 
classes, a claim while under the influence of alcohol by three classes also, both penalties being cumulative. So a young driver causing a claim while under the influence of alcohol and then running away would be penalized by 10 classes!

Finally note that the insurers have accepted to redistribute to the policyholders the income increase generated by the stricter transition rules; the basic premium would be progressively decreased, according to a scheme to be devised with the control authorities. So the implementation of the new system should induce, in the long run, higher premium rebates to the best drivers and stiffer penalties to the worst risks.

\section{PRESENT STATE OF DISCUSSIONS (AUGUST 1987)}

The preceding proposal was presented to the Control Authorities and representatives of the Ministère des Affaires Economiques. All our suggestions were accepted but two:

(i) the penalization for hit-and-run claims: the Supervising Authorities felt that insurance companies cannot pretend to substitute themselves for civil courts;

(ii) the starting class of the bonus-malus system: the delegate of the Ministère des Affaires Economiques was of the opinion that the starting level for any merit-rating system had to be 100 , so the starting class of our system had to be class 7 . He could not be convinced by the argument that premium levels in fact do not mean much, and that we could for instance multiply all levels by $100 / 130$, so as to have a starting level of 100 in class 10 . Therefore a new system was elaborated with the Control Authorities (see Table 9).

TABLE 9

\begin{tabular}{cc}
\hline Class & Premium level \\
\hline 19 & 200 \\
18 & 185 \\
17 & 171 \\
16 & 159 \\
15 & 147 \\
14 & 136 \\
13 & 126 \\
12 & 117 \\
11 & 108 \\
10 & 100 \\
9 & 93 \\
8 & 86 \\
7 & 79 \\
6 & 73 \\
5 & 68 \\
4 & 63 \\
3 & 58 \\
2 & 54 \\
1 & 50 \\
\hline
\end{tabular}


TABLE 10

\begin{tabular}{lc}
\hline \hline Efficiency & $19.6 \%$ \\
$\begin{array}{l}\text { Relative stationary } \\
\text { average level }\end{array}$ & $18.2 \%$ \\
$\begin{array}{l}\text { Average optimal } \\
\text { retention }\end{array}$ & $10,064 \mathrm{frs}$. \\
$\begin{array}{l}\text { Maximal optimal } \\
\text { retention }\end{array}$ & $73,100 \mathrm{frs}$. \\
\hline
\end{tabular}

The starting class was to be 10 , with transition rules:

reduction of one class for each claim-free year; penalization of three classes for the first claim and by four classes for each subsequent claim in the same year.

One class was added so as to have as many bonus classes as malus classes. The premium levels were devised so as to form a geometric progression: the ratio between two consecutive levels is equal (before rounding off) to 184 . So the penalty for each claim will be proportional to the premium level previously attained. Obviously this system only differs imperceptibly from the former proposal, as shown by the results of our program runs (Table 10). Yet its elegance and symmetry managed to receive the adhesion of all parties concerned.

The proposal was then submitted to the companies affiliated to the UPEA for criticism. Minor practical remarks were made, that led to a slight decrease in the penalty for young drivers and for claims with aggravating circumstances. Many suggestions were made, and are currently being analysed by the study group.

A practical problem, that has nothing to do with the tariff structure, may however considerably delay the reform. Indeed the standard policy sold by the insurers for the moment is a five-year contract renewable by tacit reconduction. A policyholder can only cancel his policy at the expiration of the five-year term or if tl:a contract is modified, which will obviously be the case if the new bonusmalus system is introduced. The latest such modification occurred in 1978; it resulted in a lot of cancellations; many policyholders left their traditional company to join one of the Direct Writers. Clearly most insurers are not willing to endure the same experience; they are not prepared to risk their market share for the intellectual pleasure of applying a fairer tariff.

The problem is further complicated by major modifications that are likely to completely upset the Belgian market in the near future:

- Several important Direct Writers have announced the creation of an automobile department.

- A recent wave of consumerism is now creating a lot of turmoil. The leading consumers' association has published several articles that strongly criticize the traditional companies. The daily press made headlines of those criticisms, thereby providing free advertising to the Direct Writers.

- The Minister of Economic Affairs has threatened to completely liberalize the 


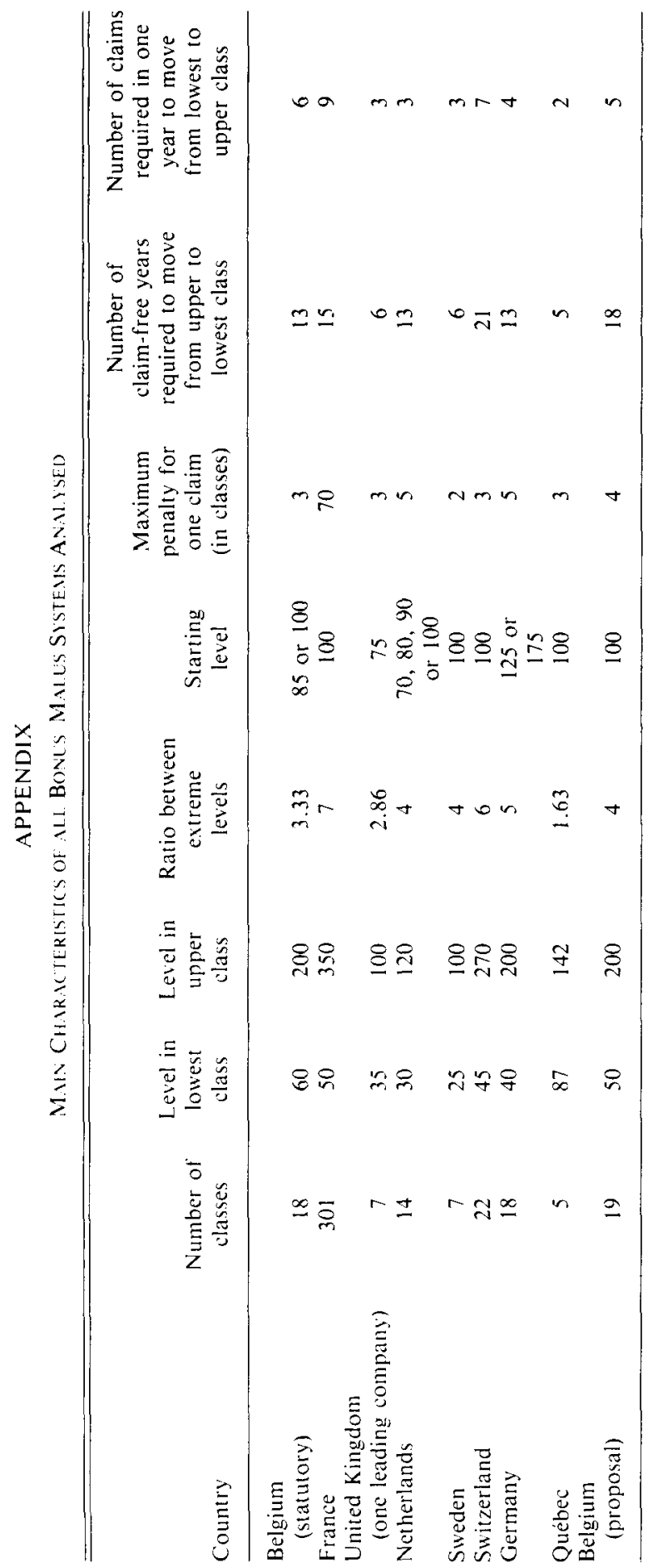


tariffs for trucks. It is an understatement to say that most companies are frightened by the idea that this measure could be extended to all categories of vehicles.

- The Minister of Economic Affairs is planning a Decree that would make it possible for the policyholders to cancel their policy once a year. This would provide another advantage to the Direct Writers.

- The Second Directive of the EEC Council (December 30,1983) is scheduled to be applied on January 1, 1989. It implies a complete rewording of the policies.

- The Belgian market is for the moment relatively protected from competition from foreign insurers. EEC regulations will suppress existing barriers at the latest in 1993.

Obviously Belgian insurers expect a tremendous competition in the years to come. So there is a possibility that the introduction of the new tariff structure could be delayed by several years, in order to avoid giving too many opportunities to new competitors to penetrate the market.

\section{REFERENCES}

Lemaire, J. (1985) Automobile Insurance: Actuarial Models. Kluwer, Boston.

LoImARANTA, K. (1972) Some asymptotic properties of bonus systems. ASTIN Bulletin 6, $233-245$.

Van Eeghen, J., Greup, E and Nijssen, J. (1983) Rate Making. Nationale Nederlanden.

JEAN LEMAIRE

Wharton School, University of Pennsylvania, 3641 Locust Walk, Philadelphia, PA 19104, USA. 